\title{
EMPREENDEDORISMO SOCIAL E COOPERATIVISMO SOLIDÁRIO NA AGRICULTURA FAMILIAR
}

Social entrepreneurship and solidarity cooperative in family agriculture

Emprendimiento social y cooperativismo solidario en agricultura familiar

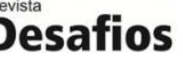

\section{Eliane Alves da Silva ${ }^{* 1}$, Dércio Bernades de Souza², Gleimiria Batista da Costa $^{3}$, Eugenio Avila Pedrozo ${ }^{4}$, Tania Nunes da Silva ${ }^{5}$}

Artigo Original Original Article Artículo Original

${ }^{1}$ Núcleo de Ciências Sociais Aplicadas, Programa de Pós-Graduação em Administração, Universidade Federal de Rondônia, Porto Velho, Brasil.

*Correspondência: Núcleo de Ciências Sociais Aplicadas (NUCSA), Programa de Pós-Graduação em Administração, Campus José Ribeiro Filho, BR364, KM 9,5, sentido Rio Branco s/n ${ }^{o}$, Porto Velho, Rondônia, Brasil.CEP:76815-800.e-mail elianealvesil@yahoo.com.br.

Artigo recebido em 09/01/2020 aprovado em 18/05/2020 publicado em 04/08/2020.

\section{RESUMO}

O cooperativismo solidário pode ser uma forma de institucionalização para um empreendimento social. Sendo importante em um cenário onde há necessidade de se desenvolver uma economia alternativa onde a exploração pode ser evitada. Portanto o objetivo deste artigo é analisar o impacto social do cooperativismo solidário em uma cooperativa de agricultura familiar em Porto Velho-RO. Optou-se por uma pesquisa empírica por meio de um estudo de caso qualitativo exploratório-descritivo. Após analisar os relatos, verificou-se que a cooperativa solidária para se fortalecer deveria focar mais na inclusão cultural, buscando por aprendizagem uma relacionada à economia solidária, capacitando seus membros na construção de inovações que permitam maior sustentabilidade. A COOPAFARO é a expressão dos interesses e necessidades dos associados, extensão de suas economias, caracterizada pela associação e pela instrumentação empresarial, viabilizada pela participação e pela inteligência coletiva. Verificou-se que a participação política, a qual influência a dimensão econômica, é uma questão central na administração do empreendimento cooperativo. As políticas públicas voltadas para a agricultura familiar, são meios para atingir o fim social.

Palavras-chave: Agricultura Familiar, Cooperativismo Solidário, Empreendedorismo Social.

\section{ABSTRACT}

Solidarity cooperativism can be a way of institutionalization for a social enterprise. Being important in a scenario where it is necessary to develop an alternative economy where exploitation can be avoided. Therefore, the aim of this paper is to analyze the social impact of cooperative solidarity in a family farming cooperative in Porto VelhoRO. It was chosen an empirical research through an exploratory-descriptive qualitative case study. After analyzing the dialogues, it was found that cooperative solidarity to become stronger, it needs focusing on cultural inclusion, seeking to learn more about solidarity economy, enabling its members in the construction of innovations that allow greater sustainability. COOPAFARO is an expression of the interests and demands of the members, extension of their sales, characterized by the association and the business instrument, made possible by participation and collective intelligence. Political participation, which is the influence of the economic dimension, was found to be a central issue in the management of cooperative enterprise. Public policies aimed at family farming, they are means to get the social.

Keywords: Family Farming, Solidarity Cooperatives, Social Entrepreneurship.

\section{RESUMEN}

El cooperativismo solidario puede ser una forma de institucionalización para un emprendimiento social. Siendo importante en un escenario donde hay necesidad de desarrollarse una economía alternativa donde la explotación 
puede ser evitada. Por lo tanto, el objetivo de este artículo es analizar el impacto social del cooperativismo solidario en una cooperativa de agricultura familiar en Porto Velho-RO. Se optó por una investigación empírica por medio de un estudio de caso cualitativo exploratório-descriptivo. Después de analizar los relatos, se verificó que la cooperativa solidaria para fortalecerse debería enfocar más en la inclusión cultural, buscando por aprendizaje una relacionada a la economía solidaria, capacitando sus miembros en la construcción de innovaciones que permitan mayor sustentabilidad. La COOPAFARO es la expresión de los intereses y necesidades de los asociados, extensión de sus economías, caracterizada por la asociación y por la instrumentación empresarial, viabilizada por la participación y por la inteligencia colectiva. Se verificó que la participación política, la cual influencia la dimensión económica, es una cuestión céntrica en la administración del emprendimiento cooperativo. Las políticas públicas vueltas para la agricultura familiar, son medios para alcanzar el fin social.

Palabras clave: Agricultura Familiar, Cooperativas Solidarias, Emprendimiento Social.

\section{INTRODUÇÃO}

Dees, referido frequentemente como o pai da educação para o empreendedorismo social (DAVIS, 2002; DEFOURNY; NYSSENS, 2017; McCULLOCH; RIDLEY-DUFF, 2019), baseia-se no pensamento dos economistas Jean-Baptiste Say e Joseph A. Schumpeter para explicar o seu conceito. Assim sendo, ele afirma que, tal como os empreendedores melhoram a capacidade produtiva da sociedade ao serem os "incentivadores e inovadores do progresso econômico", os empreendedores sociais fazem o mesmo para a mudança social, desenvolvendo novas combinações de pessoas e recursos que melhoram visivelmente a capacidade da sociedade para resolver os problemas, considerando, desta forma, o empreendedor social como um tipo de empreendedor (DAVIS， 2002; DEES， 2001; DEFOURNY; NYSSENS, 2017; McCULLOCH; RIDLEY-DUFF, 2019).

De acordo com Dees (2001), os empreendedores sociais criam valor público, procuram novas oportunidades, inovam e adaptam-se, agem de forma audaz e apresentam um forte sentido de responsabilidade. Sob este ponto de vista, o empreendedorismo social amplia a definição de empreendedorismo ao pôr ênfase na integridade ética e maximização do valor social ao invés de valor privado ou lucro (DAVIS, 2002; DEFOURNY; NYSSENS, 2017). Em meio a esses conceitos o cooperativismo, pode ser uma forma de institucionalização para um empreendimento social.

O cooperativismo é norteado por um estilo de administração humanista, por princípios que estabelecem maior vínculo com as pessoas, primando tanto o lucro como o crescimento das pessoas, tendo como meta, promover por meio da união, a sustentabilidade dos menos favorecidos (ACI, 2011). Já o modelo solidário vai muito mais além, pois defende que, para construir esta economia é necessário rever a forma de compreensão do desenvolvimento, garantindo autonomia e fortalecimento das dinâmicas locais, ampliando o protagonismo das lideranças e organizações sociais (ZANCO, 2016; ZANCO et al., 2019).

Há necessidade de se desenvolver uma economia alternativa onde a exploração pode ser evitada, novas perspectivas de ocupação produtiva e reforçar trajetórias de inclusão social e conservação ambiental. Um cenário alternativo e desejado, que contemple um "novo modelo de desenvolvimento", com interação sistêmica entre atores e instituições para alcançar objetivos de crescimento, inovação, competitividade, equidade e sustentabilidade. Sendo assim, provocar reflexões sobre uma economia solidária, oferecendo inovações sociais que tragam 
desenvolvimento sustentável confere relevância a este estudo. Com base nessa contextualização, a presente pesquisa, tem por objetivo analisar o impacto social do cooperativismo solidário em uma cooperativa de agricultura familiar em Porto Velho-RO.

Para atingir o objetivo proposto optou-se por uma pesquisa empírica por meio de um estudo de caso qualitativo exploratório-descritivo na Cooperativa de produtos e serviços agrícolas de agricultores familiares dos estados de Rondônia (COOPAFARO), situada no município de Porto Velho. Foram entrevistados 3 cooperados, uma técnica da Empresa de Assistência Técnica e Extensão Rural do Estado de Rondônia (EMATER-RO) e uma representante da Secretaria Municipal de Agricultura e Abastecimento (SEMAGRIC) por meio de entrevistas semiestruturadas e posteriormente analisadas segundo as categorias de análise: desenvolvimento local, inclusão social, inclusão produtiva, inclusão cultural e inclusão econômica.

O artigo está estruturado em 7 seções. Além do presente aspecto contextual introdutório, foram explorados da segunda à quinta seções os referenciais teóricos de empreendedorismo social, e cooperativismo solidário e cooperativismo solidário no Brasil. Na quinta seção são apresentados os procedimentos metodológicos utilizados no estudo. $\mathrm{Na}$ sexta seção são discutidos e analisados os resultados encontrados pelo estudo empírico. Como última seção, conclui-se as análises desenvolvidas, bem como propõem-se novos estudos na temática.

\section{EMPREENDEDORISMO SOCIAL}

Há uma vulgarização do conceito de empreendedorismo social, este foi sendo entendido em diversos sentidos, tornando-se confuso (DEES, 2001; DEFOURNY; NYSSENS, 2017). Alguns autores o associam à criação de uma organização não lucrativa, outros a empresas com fins lucrativos que integram ações de responsabilidade social e outros, ainda, a empresas sociais com negócios sociais (DEES, 2001; DEFOURNY; NYSSENS, 2017). Contudo, existe um consenso na doutrina no sentido de que no empreendedorismo social, a criação de valor social é o objetivo principal. Logo, a criação de valor social consistirá em encarar novos desafios sociais de forma eficaz, por meio de criatividade e inovação no desenvolvimento de modelos de negócios. Por isso é indispensável a criação de valor econômico, considerando a sustentabilidade da iniciativa $\mathrm{e}$ autossuficiência financeira (DEES, 2001; DEFOURNY; NYSSENS, 2017; McCULLOCH; RIDLEY-DUFF, 2019; MAIR; MARTI, 2006).

Apesar da emergência do empreendedorismo social, tanto a nível acadêmico como empresarial, ainda há alguma tensão na literatura quanto à sua definição exata (ALEGRE; KISLENKO, 2017; CERTO; MILLER, 2008; CONWAY; KALAKAY, 2016). O número de definições utilizadas para descrever o fenômeno do empreendedorismo social aumentou consideravelmente. De fato, o termo “empreendedorismo social” significa coisas diferentes para pessoas diferentes e significa, também, coisas diferentes para pessoas em locais diferentes (ALEGRE et al., 2017; CONWAY; KALAKAY, 2016; MAIR, 2010;). Logo, há um conceito complexo, não existindo na literatura consenso sobre mesmo (ZAHRA, et al., 2008)

Como a primeira vertente do empreendedorismo social, destaca-se a criação de valor social (missão social). Efetivamente, o objetivo do empreendedorismo social é a criação de valor social, por meio de incentivo de mudança social e/ou reparando as necessidades sociais (ALEGRE et al., 2017; DEFOURNY; NYSSENS, 2017; MAIR; MARTI, 2006; PEREDO; MCCLEAN, 2005) e os empreendedores sociais fazem-no adotando uma missão social (DEES, 2001; DEFOURNY; 
NYSSENS, 2017; McCULLOCH; RIDLEY-DUFF, 2019). A missão social traduzida na criação de valor social representa, portanto, uma das principais dimensões caracterizadoras do empreendedorismo social.

A segunda vertente diz respeito ao impacto social, o que é considerado um diferenciador fundamental (ALEGRE; KISLENKO, 2017; AUSTIN et al., 2006; CONWAY; KALAKAY, 2016). A este propósito, Dees (2001) menciona que o lucro, a criação de riqueza e a satisfação dos desejos dos clientes constituem meios para atingir um fim social e não o fim em si mesmo. O lucro e a satisfação do cliente não são indicadores da criação de valor, mas sim o impacto social, ou por outras palavras, o desempenho social (CONWAY; KALAKAY, 2016; DEES, 2001). Porém, Mair e Marti (2006) referem que a avaliação do desempenho social (ou impacto social) é um dos grandes desafios para os profissionais e pesquisadores de empreendedorismo social na medida em que a verdadeira dificuldade pode não ser a medida em si, mas a forma como as medidas podem ser utilizadas para quantificar o desempenho e/ou impacto do empreendedorismo social. Também Austin et al. (2006) indicam que medir a mudança social se transforma numa dificuldade, particularmente, devido a fatores como dimensões temporárias ou diferenças na percepção do impacto social criado.

A sustentabilidade vista como caraterizadora do empreendedorismo é característica da terceira vertente. Para Weerawardena e Mort (2006), na mesma medida em que os resultados comprovam o papel principal da missão social, também o esforço constante para garantir a sustentabilidade é importante. No empreendedorismo social, apesar da criação de valor social ser o propósito principal, a criação de valor econômico é imprescindível para garantir a sustentabilidade económica da iniciativa e autossuficiência financeira (DEFOURNY;
NYSSENS, 2017; MAIR; MARTI, 2006; OECD, 2010), ou seja, o valor económico serve objetivos sociais (OECD, 2010). O modelo de negócio tem de seguir a estratégia de impacto social, mas dentro dessa limitação, os empreendedores sociais atuam para desenvolver empreendimentos sustentáveis (DEES, 2011; DEFOURNY; NYSSENS, 2017).

Enquanto a quarta vertente reporta-se aos modelos de governança adotados pelas organizações socialmente empreendedoras. Tais modelos de governança assentam nos valores da transparência, participação, democracia, responsabilidade, autonomia e independência. $\mathrm{O}$ poder de decisão não se baseia na propriedade de capital (DEFOURNY; NYSSENS, 2012). Tal demonstra que a organização aplica o princípio de "um membro, um voto" (DEFOURNY; NYSSENS, 2012).

Já a quinta vertente é baseada na perspectiva europeia. Considera que a finalidade não lucrativa (ou pelo menos que a finalidade lucrativa não seja a título principal) é outra dimensão caracterizadora do empreendedorismo social. O modo de apropriação do valor econômico não tem, assim, como parâmetro a participação no capital social.

A sexta vertente do empreendedorismo social, da qual este estudo se apoia, é a inovação social. Entende-se por inovação social o conjunto de "atividades e serviços inovadores que são motivados pelo objetivo de satisfazer uma necessidade social e que são predominantemente desenvolvidas e difundidas por meio de organizações cujos efeitos primordiais são sociais" (MULGAN, 2007). A inovação social refere-se à inovação tradicional em termos de criação de valor cujo objetivo final é, não só criar valor econômico, como também reforçar a instituição social (DEFOURNY; NYSSENS, 2017; HARAYAMA; NITTA, 2011; McCULLOCH; RIDLEY-DUFF, 2019). A inovação social surge da empresa social ou do empreendedorismo social. No 
entanto, também pode surgir em muitos outros contextos e, embora o empreendedorismo social envolva muitas vezes a inovação, apenas uma pequena minoria de empreendedores sociais cria novos modelos que podem ser replicados (MULGAN, 2007).

\section{A IDENTIDADE COOPERATIVA E COOPERATIVISMO SOLIDÁRIO}

Do conceito de inovação social se retira fundamentalmente, as seguintes notas: criação pela organização não de apenas valor econômico, mas também de valor social, seguindo novas estratégias, beneficiando de oportunidades e desenvolvendo novas formas de interação para dar resposta a questões sociais. A compreensão da inovação social nas cooperativas passa, fundamentalmente, pelo seu confronto com a sociedade comercial.

Assim, como destaca Parnell (2012), as cooperativas caracterizam-se por: a) serem centradas nas pessoas, ao contrário das sociedades comerciais que controladas pelos investidores, centrando-se, por isso, no capital; b) terem sempre um propósito econômico e funcionarem como empresas que operam no mercado, ainda que operando de acordo com os preceitos econômicos da cooperação, o que significa que as cooperativas procuram a otimização de recursos, em vez da maximização de benefícios (como acontece com as sociedades comerciais); c) funcionarem sob posse e controle dos seus membros; d) assentarem nos valores de autoajuda e ajuda mútua; e) existirem principalmente para benefício dos seus membros; f) reinvestirem os seus benefícios na organização, afetando-os a reservas; g) basearem-se na genuína cooperação; h) e, por último, assentaram na regra da distribuição desinteressada.

Já o Cooperativismo Solidário é pautado pela concepção de que os empreendimentos solidários manifestam outro modo de produção, ou uma outra economia (CATTANI, 2003; GAIGER; KUYVEN,
2020). Essas organizações funcionam na base da solidariedade, autogestão e cooperação e se fortalecem a partir da busca pela igualdade social, na autonomia institucional e na gestão democrática, com participação e igualdade social (BRASIL, 2015). Seu objetivo não é a busca pelo lucro, mas pela promoção do desenvolvimento com inclusão social, produtiva, cultural, econômica dos associados e da comunidade local. Diferente das empresas tradicionais, o Cooperativismo Solidário entende a organização como sistema cultural, simbólico e imaginário que avança no envolvimento das pessoas para além do capital.

O Cooperativismo é norteado por um estilo de administração humanista, por princípios que estabelecem maior vínculo com as pessoas, primando tanto o lucro como o crescimento das pessoas, tendo como meta, promover por meio da união, a sustentabilidade dos menos favorecidos. O desafio do gestor de cooperativas é corroborar para o crescimento das pessoas, por isso, o esforço de gerir uma cooperativa auto gestionária passa pelos esforços de se comunicar e de relacionar permanentemente com os sócios e clientes, buscando garantir o funcionamento da organização auto gestionária e a sua sobrevivência no mercado, mantendo-se na ótica do solidário que busca inclusão sustentável, valorização da diversidade ambiental, soberania e identidade regional, em síntese, outra economia.

O modelo solidário defende que, para construir esta economia é necessário rever a forma de compreensão do desenvolvimento, garantindo autonomia e fortalecimento das dinâmicas locais, ampliando o protagonismo das lideranças $\mathrm{e}$ organizações sociais (GAIGER; KUYVEN, 2020; ZANCO, 2016). Esse cooperativismo defende estratégias de desenvolvimento, procurando conciliar a necessidade de desenvolvimento econômico, com a inclusão social e fortalecimento das pessoas, pois somente com participação ativa das pessoas o 
desenvolvimento será sustentável, com a construção de propostas, aprovação de Leis e execução de programas estruturais. (UNICAFES, 2018).

O empoderamento não depende de características das pessoas beneficiadas ou da intervenção de experts que objetivam desenvolver habilidades adequadas, mas depende, crucialmente, das redes e das capacidades estratégicas que interrelacionam os projetos dos atores particulares com outros e da expansão do espaço de interface (GAIGER; KUYVEN, 2020; LONG, 2001).

Neste contexto surge a noção de agência, como capacidade de fazer estas coisas, afirmando que todos os atores exercem um determinado tipo de poder, mesmo aqueles em posições de extrema subordinação. O cooperativismo é ferramenta importante capaz de viabilizar a permanência da agricultura familiar no campo e identificar instrumentos para promoção do desenvolvimento contemplando as dimensões econômica, social e humana. O desenvolvimento econômico, como discutido sob a ótica de vários autores, advém, entre outros fatores, de um processo de geração e distribuição de renda, de forma justa e igualitária entre os indivíduos de uma população (UNICAFES, 2018).

O Cooperativismo Solidário abriga vários segmentos sociais, mas sua origem é fortemente arraigada pelos movimentos sociais do campo e com relação direta com a agricultura familiar. Sua fundação é marcada com um movimento de resistência política e ideológica que é constituído para força as pessoas que se encontravam à margem dos processos de desenvolvimento. As Cooperativas Solidárias são marcadas pelas relações de proximidade, pela relação direta entre os diretores da cooperativa e os seus associados, gerando assim maior confiabilidade nas relações internas e externas do segmento (UNICAFES, 2018).

\section{COOPERATIVISMO SOLIDÁRIO NO BRASIL}

Entre os anos 1995 e 2005, ocorreram vários processos de articulação destas Cooperativas, com realização de vários encontros de porte territorial e nacional, sendo constatada a necessidade de construção de novos instrumentos de representação que fossem constituídos de forma legítima e participativa (UNICAFES, 2018).

A partir da década de 1990, ao lado das cooperativas empresárias e de processos isolados, surgem alguns movimentos articulados de constituição de cooperativas com base expressiva na agricultura familiar com fundamentação no princípio da Economia Solidária. Por se formarem fora dos esquemas tradicionais do cooperativismo, na época, essas organizações ficaram mais conhecidas pelos adjetivos "alternativas, populares e/ou participativas", pelo forte vínculo social. São cooperativas que atuavam especialmente no ramo do crédito, produção agropecuária, trabalho e serviços (UNICAFES, 2018).

O termo "solidário", que grande parte dessas cooperativas passou a se auto adjetivar posteriormente, além demarcar um campo político próprio de articulação que emergiu dentro do cooperativismo brasileiro, pretendeu sinalizar um conjunto de procedimentos que norteavam o funcionamento dessas organizações e que futuramente geraria uma organização de representação nacional. Com advento dos movimentos de luta pela democratização do Estado Brasileiro, há uma retomada dos movimentos sindicais e ressurge a ideia do cooperativismo como instrumento de democratização econômica dos trabalhadores e do país. A base fundante da organização cooperativa é articular pessoas em torno de um objetivo comum, e em meados de 1990, o cooperativismo desponta como a estratégia das organizações e movimentos sociais para retomar o ideário democrático (UNICAFES, 2018). 
Este cooperativismo que renasce das bases dos movimentos sociais urbanos e rurais, têm uma intenção muito semelhante ao movimento cooperativo de vertente socialista que nasceu na Europa amparado pela finalidade de inclusão econômica e social, de trabalhadores que enfrentavam problemas causados pelo modelo de desenvolvimento. Notadamente, a partir de 1990, quando o país viveu a fase de abertura comercial e as empresas do setor produtivo tiveram a necessidade de reestruturação como exigência para sua sobrevivência e inserção no mercado competitivo internacional (UNICAFES, 2018).

Segundo Calgaro (2016). As exigências provocaram crescimento da reserva de trabalhadores pelo enxugamento no número de vagas de trabalho, gerando desemprego no setor industrial e alocação de parte da reserva no setor de serviços. Esta nova conjuntura de grande desemprego, colocou trabalhadores na necessidade de assumir a indústria, afora falida, para que pudesse ter o trabalho e dele sobreviver com sua família. A mudança de trabalhador empregado, para trabalhador proprietário, gera um conjunto de novas atitudes nos trabalhadores envolvidos.

Tal mudança requer alterações nas exigências historicamente construídas (de trabalhador alienado). Ampliam-se, tantas funções quanto às responsabilidades, que exigem maior nível de informação, capacidade para participar e argumentar em discussões e deliberar assuntos de interesse da cooperativa, da participação ativa decorre da autonomia, de autodeterminação e de autorrealização dos indivíduos como trabalhadores proprietários. (CALGARO, 2016; GAIGER; KUYVEN, 2020).

Assim como o movimento de Rochdale, o movimento do Cooperativismo da Agricultura Familiar e Economia Solidária também foi construído e gestado durante períodos de recessão econômica e restrição das políticas de desenvolvimentos. Este contexto gerou um movimento de resistência política, social e econômica. Esse processo gera articulações de porte setorial e organização representativa do Cooperativismo da Agricultura Familiar, Reforma Agrária e Economia Solidária (UNICAFES, 2018).

O Cooperativismo Solidário é pautado pela concepção de que os empreendimentos solidários manifestam outro modo de produção, ou uma outra economia (CATTANI, 2003; GAIGER; KUYVEN, 2020). Essas organizações funcionam na base da solidariedade, autogestão e cooperação e se fortalecem a partir da busca pela igualdade social, na autonomia institucional e na gestão democrática, com participação e igualdade social (BRASIL, 2015). Diferente das empresas tradicionais, o Cooperativismo Solidário entende a organização como sistema cultural, simbólico e imaginário que avança no envolvimento das pessoas para além do capital.

\section{METODOLOGIA}

O estudo caracteriza-se por ser qualitativo. Neste tipo de investigação, os pesquisadores estão interessados em entender "como as pessoas dão sentido ao seu mundo e quais as experiências que têm no mundo" (MERRIAM, 2009). Para analisar o impacto social do cooperativismo solidário em uma cooperativa de agricultura familiar em Porto VelhoRO, utilizou-se do estudo de caso exploratóriodescritivo.

Trata-se de um caso intrínseco (STAKE, 2000), orientado para a singularidade, pois buscou, a partir daquilo que emergiu da prática, compreender situações, responder questões e resolver um quebracabeça (MERRIAM, 2009). Segundo Yin (2009), existem múltiplas fontes de evidências, no presente caso foram documentos, entrevistas e observações. É considerado um estudo exploratório, pois buscou-se ouvir os participantes e desenvolver um entendimento baseado nas ideias deles (MERRIAM, 2009). É 
descritivo, pois detalha o relato sobre um fenômeno a fim de ilustrar sua complexidade considerando os diversos atores envolvidos (GODOY, 2010; STAKE, 2000).

Efetuou-se análise de documentos internos fornecidos pelos entrevistados como a tabela de preço a ser praticada pelos agricultores cadastrados no Programa Nacional de Alimentação Escolar (PNAE), emitida pela SEMAGRIC; Modelo de projeto de venda de gêneros alimentícios da agricultura familiar para alimentação escolar, fornecido pela EMATER; e por fim, o estatuto da COOPAFARO. Houve complementação das informações por meio de dados secundários provenientes da página eletrônica da EMATER e da UNICAFES.

Neste estudo, um dos métodos adotados para a coleta de dados recaiu sobre entrevistas semiestruturadas. Este tipo de entrevista define um conjunto de tópicos a abordar e tem como vantagem a flexibilidade na exploração de respostas (QUIVY; CAMPENHOUDT, 2003; SOUSA; BAPTISTA, 2011). Esta escolha permitiu um conhecimento profundo para alcançar o objetivo do estudo.

A organização escolhida para prosseguir com o objetivo desta investigação foi a Cooperativa de produtos e serviços agrícolas de agricultores familiares dos estados de Rondônia (COOPAFARO), filiada à UNICAFES (União de Cooperativas da Agricultura Familiar e Economia Solidária). Essa organização entende que as cooperativas solidárias se configuram como um instrumento importante para se alterar o ambiente social e econômico de todas as regiões do Brasil (ZANCO et al, 2018).

Foram entrevistados 3 cooperados, uma técnica da EMATER-RO e uma representante da Secretaria Municipal de Agricultura e Abastecimento (SEMAGRIC). O quadro 01 apresenta as categorias de análise.
Quadro 1 - Categorias de análise.

\begin{tabular}{|c|c|}
\hline $\begin{array}{ll}\begin{array}{l}\text { Categorias } \\
\text { análise }\end{array} & \text { de } \\
\end{array}$ & Subcategorias de análise \\
\hline $\begin{array}{l}\text { Desenvolvimento } \\
\text { local }\end{array}$ & $\begin{array}{l}\text { - Há autonomia } \\
\text { fortalecimento das dinâmicas } \\
\text { locais; } \\
\text { - Ocorre protagonismo das } \\
\text { lideranças e organizações } \\
\text { sociais. }\end{array}$ \\
\hline Inclusão social & $\begin{array}{l}\text { - O Cooperativismo, promove } \\
\text { por meio da união, a } \\
\text { sustentabilidade dos menos } \\
\text { favorecidos. }\end{array}$ \\
\hline $\begin{array}{l}\text { Inclusão } \\
\text { produtiva }\end{array}$ & $\begin{array}{l}\text { - Nova racionalidade } \\
\text { produtiva apoiada na } \\
\text { solidariedade; } \\
\text { - O trabalho da cooperativa } \\
\text { atua a favor dos próprios } \\
\text { produtores; } \\
\text { - Qualidade de vida dos } \\
\text { trabalhadores e a satisfação } \\
\text { de objetivos culturais e ético- } \\
\text { morais. }\end{array}$ \\
\hline Inclusão cultural & $\begin{array}{l}\text { - Os cooperados adquirem } \\
\text { maior nível de informação, } \\
\text { capacidade para participar e } \\
\text { argumentar em discussões e } \\
\text { deliberar assuntos de } \\
\text { interesse da cooperativa; } \\
\text { - A participação ativa decorre } \\
\text { da autonomia, de } \\
\text { autodeterminação e de } \\
\text { autorrealização dos } \\
\text { indivíduos como } \\
\text { trabalhadores proprietários. }\end{array}$ \\
\hline $\begin{array}{l}\text { Inclusão } \\
\text { econômica }\end{array}$ & $\begin{array}{l}\text { - Novas atitudes na mudança } \\
\text { de trabalhador empregado, } \\
\text { para trabalhador proprietário. }\end{array}$ \\
\hline
\end{tabular}

Fonte: Autores

Com base nos dados coletados, buscou-se analisar as respectivas categorias de análise a luz das abordagens teóricas apresentadas.

\section{RESULTADOS E DISCUSSÕES}

O Cooperativismo Solidário funciona com base na solidariedade, autogestão e cooperação, tendo como objetivo a promoção do desenvolvimento com inclusão social, produtiva, cultural, econômica dos associados e da comunidade local. Quanto mais atende 
esses pontos maior é o impacto causado por essa inovação social.

A COOPAFARO foi fundada em dezembro de 2015, por agricultores familiares do Projeto de Assentamento Joana D'arc III, na Agrovila Chico Mendes. Os problemas que enfrentavam eram caracterizados pela baixa organização dos produtores, falta de regularização fundiária, além da dificuldade de escoamento da produção. O intuito era buscar a formalização para que o cooperados pudessem participar do Programa Nacional de Alimentação Escolar (PNAE). Inicialmente foram 15 famílias provenientes de uma associação, mas que logo evoluiu para uma cooperativa. Observou-se em uma declaração de um dos cooperados a inclusão social, por meio de novas estratégias, beneficiando de oportunidades e desenvolvendo novas formas de interação para dar resposta a questões sociais.

No início tudo é muito difícil né quando a gente começou aí muito tempo atrás era bem pequenininho a nossa estrutura nois entregava numa moto numa carretinha e a gente se programava para fazer a entrega em dois dias e a nossa propriedade da 80 $\mathrm{km}$ da cidade então tinha uma grande dificuldade e todos os produtores vinha a até a cidade para trazer os produtos deles, entendeu? Então com a dificuldade que a gente tinha para poder todo mundo se locomover a gente primeiro teve uma associação no Joana D'arc aonde criamos ali uma comissão que vinha fazer esse trabalho, não precisava todos os produtores vir [...] E aí depois a gente pegou e achou melhor criar uma cooperativa aí nois só foi crescendo e dentro da cooperativa a gente tem várias comissão para poder fazer a entrega a parte da logística (Entrevistado A).

Neste mesmo trecho da entrevista verificou-se a inclusão produtiva, pois com o novo formato de trabalho devido à implantação da cooperativa, os agricultores foram favorecidos, além de adquirirem uma certa qualidade de vida.

Neste outro recorte, observa-se a inclusão produtiva por meio da criação da cooperativa e suas comissões para se dividir as tarefas entre os cooperados. Com a nova racionalidade pautada na solidariedade, houve maior produtividade no campo, melhor distribuição dos produtos, aumento do ganho financeiro e melhores relacionamentos interpessoais entre os produtores, onde segundo fala do cooperado deixaram de ser concorrentes para trabalharem juntos. Outra característica percebida foi a inclusão social, pois por meio da cooperativa deixaram de competir e passaram a trabalhar juntos. Ocorreu também o desenvolvimento local, pois a nova organização do trabalho foi fruto da liderança da cooperativa e isso acabou fortalecendo as dinâmicas locais.

Antes ficava muito disputado, 5 vizinhos ali traziam o mesmo produto muita das vezes, traziam para poder vender no mesmo local, faziam uma concorrência entre eles mesmos. E hoje já facilitou, e por ser meio de cooperativa nóis temos uma facilidade a mais para poder atender esses órgãos públicos [... ] com isso nós ganhamos melhores preços, nóis vendemo quantidade maior, tem todo esse melhoramento através da cooperativa, facilitou muito a vida dos cooperados, todo mundo deixa de ser concorrente para trabalhar junto (Entrevistado A).

O entrevistado " $\mathrm{A}$ " fala como a cooperativa se encontra hoje, enfatizando o aumento do número de cooperados e como a estrutura que atende os agricultores melhorou em relação ao que era antes. A cooperativa consegue fortalecer os cooperados que possuem Declaração de aptidão ao PRONAF (DAP). Esse instrumento qualifica a família como da agricultura familiar, permitindo que o produtor entre nos programas como o Programa Nacional de Alimentação Escolar (PNAE) e Programa de 
Aquisição de Alimentos (PAA). Após adquirirem essa declaração os produtores também precisam de um projeto de venda de gêneros alimentícios da agricultura familiar obtida junto a EMATER-RO. Os técnicos da EMATER visitam as propriedades semanalmente, tentando conciliar a demanda de produtos procurados pelas secretarias de educação, no caso do PNAE ou pela CONAB, no caso do PAA. Porém os agricultores que não conseguem a DAP, não podem entrar nesses programas individualmente, logo eles dependem totalmente da cooperativa para comercializar seus produtos, caracterizando assim, a inclusão produtiva.

E hoje nós estamos muito melhor fazer entrega nós temos pessoas diretamente né trabalhando, os outros na parte da entrega a parte da logística [...] E hoje nós estamos muito melhor nois estamos hoje com caminhão baú, nois temos um carro pequeno para fazer entrega, 11 pessoas diretamente né trabalhando [...] Começamos com 15 cooperados né, hoje está aproximadamente 22 com DAP nois temos o total de 50 cooperado $20 \mathrm{com}$ DAP, nois temos mais 15 que tão agora aderindo junto, então vamos agregar quase 70 pessoas (Entrevistado A).

A declaração do entrevistado mostra como ocorreu a inclusão econômica, em que a princípio, agricultores que não tinham DAP, que não poderiam comercializar seus produtos por falta de documentação, passam a ser trabalhadores proprietários.

Outro cooperado mencionou um exemplo pessoal de como era antes de haver toda essa organização na formação do cooperativismo solidário. Para ele e sua família era inviável permanecer no campo. Naquela época costumavam até ter empregos não relacionados com a agricultura familiar para garantir sua subsistência. Essa experiência denota a inclusão social, pois a família do agricultor conseguiu se sustentar a partir do momento em que se associou a cooperativa. Além disso, tal relato caracteriza uma inclusão econômica, pois a família pôde se fixar na propriedade rural, trabalhando como proprietária de sua mão de obra e não mais trabalhando como empregado.

Eu me recordo que quando era jovem, nos manter na propriedade somente com o dinheiro arrecadado e ganhar do próprio sítio era muito difícil muito difícil, é nós plantávamos para subsistência também nessa época, mas sempre tínhamos que sair para fora para trabalhar, porque infelizmente o produto que você plantava, você não vendia, se vendia, você tinha que vender super barato. Não pagava nem os custeios, não pagava a adubação que naquela época era pouco, mas fazíamos também, né. então era tudo rudimentar, né, irrigação impensável você não podia, porque era tudo caro, você não tinha investimento do governo em nada, o governo não te apoiava (Entrevistado B).

Nesse mesmo relato foi possível identificar a inclusão cultural, pois houve participação ativa decorrente da autonomia, autodeterminação e de autorrealização dos proprietários.

A COOPAFARO pode ser considerada uma inovação social proveniente de economia solidária, cabe analisar com um pouco mais de profundidade a afirmação de um dos entrevistados.

Mas nois somos também associado na UNICAFES de Ji-Paraná e aí a gente sempre faz curso, já tivemos em Foz do Iguaçu, me lembro que eu passei em Foz do Iguaçu, eles tem uma experiência muito muito, são os pioneiros de Rondônia [...] Eles nos ajudaram muito, eles nos oriento na parte de gestão, entendeu, foi eles que nos orientaram muito e nos tem ajudado muito, com o conhecimento que eles tem passando pra gente (Entrevistado A). 
A UNICAFES (União de Cooperativas da Agricultura Familiar e Economia Solidária). Essa organização entende que as cooperativas solidárias se configuram como um instrumento importante para se alterar o ambiente social e econômico de todas as regiões do Brasil (ZANCO et al., 2018). Suas diretrizes são bases orientadoras para ações dos diversos ramos cooperativos, e, são inseridas nas estratégias de ação das cooperativas associadas e das centrais, fundamentando a relação entre os ramos cooperativos e as diretrizes defendidas pelo Cooperativismo Solidário (UNICAFES, 2017a; ZANCO et al., 2018).

Essa instituição promove o Programa de Educação do Cooperativismo Solidário (PECSOL), do qual tem como objetivo geral realizar ações de educação e ações de educação e formação cooperativista para qualificação da gestão e governança das cooperativas da agricultura familiar e economia solidaria filiadas ao sistema UNICAFES (UNICAFES, 2017b). Na realização do projeto piloto em Rondônia, o PECSOL tem como objetivo preliminar oferecer aos agricultores familiares organizados em cooperativas filiadas a UNICAFES/RO, formação inicial e continuada, com intuito de possibilitar um conhecimento ampliado na área de gestão e governança das cooperativas, ampliando assim as oportunidades de qualificação de produção, comercialização, além de possibilitar avanços de atributos como a autonomia, autoestima, conhecimento, empreendedorismo e assim promover a participação das cooperativas nos diversos espaços de poder e decisão (UNICAFES, 2017b).

As atividades formativas tem como missão realizar ações de educação e formação cooperativista para qualificação da participação, gestão e governança das cooperativas filiadas no Sistema UNICAFES, buscando ampliar instrumentos para consolidação das redes de cooperação, com fomento às práticas e iniciativas de autogestão, de integração de setores com estruturação de complexos de produção, comercialização e consumo. Esses instrumentos ajudam intercooperação e aprendizado mútuo entre os empreendimentos (UNICAFES, 2017b).

Segundo a UNICAFES (UNICAFES, 2017b), o esquecimento da participação social e da Educação Cooperativista por parte dos cooperados é um dos principais problemas encontrados nas cooperativas, por isso os gestores precisam fortalecer a sua relevância no desenvolvimento da gestão cooperativa, podendo, dessa forma alcançar os seus objetivos, sendo fundamental fortalecer as estratégias de educação e aprendizagem cooperativista, com programas de porte geral, executado com várias organizações em paralelo.

Esse exemplo enfatiza a inclusão cultural dos cooperados, que por meio da UNICAFES, adquirem maior nível de informação e capacidade para participar e argumentar em discussões para deliberar assuntos de interesse da cooperativa. Vale ressaltar que a inclusão produtiva também foi identificada na declaração do cooperado, pois busca implantar uma postura de trabalho que atue em favor dos agricultores.

Sobre as relações da COOPAFARO com a EMATER, coube analisar as seguintes declarações tanto de um dos cooperados quanto da técnica da EMATER-RO.

Nós temos uma parceria com a EMATER, eles têm nos ajudado [...] (Entrevistado A)

[...] A EMATER incentiva e orienta muitos produtores quanto a embalagem, porque essa produção que vai ser entregue nas escolas, vai ser entregue para as famílias carentes, são pessoas né, que vão tá alimentando, então o produto tem que ser de boa qualidade, o produto não pode ter agrotóxico, é uma coisa que 
tem que ser orgânico de verdade, porque são alunos que vão usar [...] Esse mês passado a EMATER fez até uma capacitação... vou até te mostrar... nós fizemos uma cartilha de boas práticas, fabricação e manipulação de alimentos para os produtores feirantes (Entrevistada C).

A EMATER presta uma assessoria aos produtores rurais, não somente nos projetos de venda para a cooperativa participar de programas como o PNAE e o PAA, mas também na produção e no manuseio de seus produtos. Essas características mostram que a EMATER promove uma inclusão cultural. Outro retorno positivo foi o programa voltado para ações práticas de agroecologia, que atende a diversos sistemas das unidades de produção familiar, se voltando para a área vegetal com maior destaque para a produção de hortaliças e sistemas agroflorestais. A agroecologia fortalece circuitos locais e regionais e também redes de comercialização, valorizando a biodiversidade e a produção orgânica e agroecológica de alimentos, além de incentivar hábitos alimentares saudáveis e estimular o associativismo (EMATERRO, 2019). Identificou-se também o desenvolvimento local, pois o trabalho feito pela EMATER fortalece as dinâmicas sociais.

Outro exemplo de interação entre a COOPAFARO com o poder público é a participação junto ao Programa Municipal de Alimentação (PMAE), que seria um complemento ao PNAE. Esse programa complementar além de melhorar a alimentação dos alunos, oferece preços mais competitivos para os agricultores. Outra medida que reforçou o escoamento de produtos da agricultura familiar, foi a Lei municipal 2.543, de 24 de setembro de 2018. Por meio desta foi instituído o Programa Municipal de Aquisição de Alimentos da Agricultura Familiar (PMAAF), que tem como diretrizes o estímulo à organização de núcleos de produção nas comunidades rurais e a aquisição de alimentos produzidos pelos agricultores da agricultura familiar, na modalidade compra com doação simultânea e tem como parâmetro o Programa de Aquisição de Alimentos (PAA) criado pelo Artigo 19 da Lei $n^{\circ}$ 10.696, de 02 de Julho de 2003. Nota-se que ambas iniciativas privilegiam a agricultura familiar, o que denota o reconhecimento da administração do município sobre os benefícios promovidos pelo cooperativismo solidário.

Resultante do cooperativismo solidário percebe-se os reflexos no desenvolvimento local sustentável e da inclusão econômica. Foi entrevistado um produtor rural, do qual possuí uma agroindústria de poupa de frutas, que emprega 10 pessoas em sua propriedade. Além de atender as políticas públicas voltadas para a alimentação, já consegue produzir excedente para ser vendido no comércio local. Hoje esse cooperado atende a Secretaria Municipal de Educação (SEMED) e a Secretaria de Educação do Estado (SEDUC) e ainda consegue vender seu excedente para o mercado.

[...] Eu não tinha documento ainda necessário para poder participar da venda direta da merenda escolar, né, eu tinha a documentação da polpa, mas não era as exigências, que não atendia as exigências da SEMED [...] Então nós vendia mais era banana, melancia, frutas e verduras [...] Hoje eu atendo mais mercado, nós vendemos pra SEMED, pra SEDUC e nós vendemos também para outro mercado aqui da região, padarias, lanchonetes, né, e nós vendemos, fornecemos também banana. Hoje nós também tamo mais estruturado, tem a cooperativa que dá o apoio pra gente também (Entrevistado D).

Verifica-se nesse mesmo trecho da entrevista a inclusão social e a inclusão produtiva. Com a ajuda cooperativa, o agricultor conseguiu ter uma produção 
mais estável e garantir a sustentabilidade da família, além de adquirir qualidade de vida.

Outros exemplos em que o cooperativismo solidário está promovendo a inclusão produtiva e inclusão econômica se observa nas falas do entrevistado A. A nova organização produtiva trouxe qualidade de vida. Verifica-se a mudança de postura da visão de trabalhador, para trabalhador proprietário, caracterizando a inclusão econômica.

Lá nois temos o depósito onde nois deixamos os produtos perecíveis, o iogurte e polpa de fruta e temos o galpão lá na área rural que é o barracão da cooperativa, mas lá pra deixar esses produtos, nois tava tendo muita perca, porque tinha dia que acabava energia e ficava até 3 dias sem energia [...] e aí dificultava muito e aí com isso a gente criou aqui o escritório pra gente poder fazer a parte burocrática e aí também o depósito pra gente poder armazenar o produto que a gente traz pra poder distribuir pras escolas. Depois que a gente criou o escritório e o depósito pra nós melhorou cem por cento (Entrevistado A).

Nós temos interesse de mexer com frango caipira, e tal, mas ainda, há uma burocracia que junto com nosso prefeito e secretários vamos resolver e ficar apto para responder às exigências, a intenção é criar essas agroindústrias para poder vender, fortalecer mais a renda do produtor ainda. Com peixe estamos trabalhando agora (Entrevistado A).

No segundo relato além das dimensões anteriormente mencionadas percebe-se a inclusão cultural, pois há participação ativa autonomia e autodeterminação para resolver os projetos da cooperativa na perspectiva de proprietário. Ocorre também o desenvolvimento local, pois a organização social, no caso a cooperativa, é protagonista do fortalecimento das dinâmicas locais.
Vale ressaltar, que a COOPEFARO não atende apenas agricultores familiares de Porto Velho, mas também do Distrito Joana D'arc, cidades como Bandeirantes, Itapuã e Ariquemes. Os resultados tem sido positivos, pois antes da cooperativa, os agricultores não conseguiam vender todos os seus produtos, já atualmente, quando questionados sobre venda de seu excedente nas feiras, obteve-se a seguinte resposta:

[...] na verdade, nois ainda não conseguimos abranger todo esse mercado, nois tamos incentivando nossos produtores pra gente poder criar uma fonte hoje no município para poder trabalhar na área privada e pra poder atacar mais o mercado, oferecer o nosso produto e levar um produto de qualidade para as pessoas de Porto Velho (Entrevistado A).

Essa parte da entrevista mostra claramente a inclusão econômica, onde os agricultores atuam como proprietários buscando por novos mercados.

Após analisar os relatos, verificou-se que a COOPAFARO para se fortalecer deveria focar mais na inclusão cultural, buscando por aprendizagem uma relacionada à economia solidária, capacitando seus membros na construção de inovações que permitam maior sustentabilidade na cooperativa. Além disso, desenvolver ações para fortalecer a aprendizagem pessoal e coletiva é fundamental.

A inclusão cultural é importante, pois somente por meio desta, pode-se ampliar a inclusão social. O cooperado deve ter em mente que participa de um movimento social, que luta pela mudança da sociedade, por uma forma diferente de desenvolvimento, que não seja baseado nas grandes empresas nem nos latifúndios, mas sim um desenvolvimento a partir dos valores da solidariedade, da democracia, da cooperação, da preservação ambiental e dos direitos humanos. 
A COOPAFARO é a expressão dos interesses e necessidades dos associados, extensão de suas economias, caracterizada pela associação e pela instrumentação empresarial, viabilizada pela participação e pela inteligência coletiva, sendo fundamental a realização de um processo dinâmico de construção da inteligência coletiva, fundamentada na construção da aprendizagem.

Notou-se que a participação política, a qual influencia a dimensão econômica, é uma questão central na administração do empreendimento cooperativo. As políticas públicas como PNAE, PMAE, PMAAF e PAA, são meios para atingir o fim social. É importante ressaltar que a COOPAFARO foi criada para atender o PNAE, grande parte da produção dos cooperados é destinada ao programa, embora ocorra exceções.

O impacto social causado pelo cooperativismo solidário existe, conforme visto nos relatos dos entrevistados. Ocorreram mudanças importantes que influenciaram no desenvolvimento local, porém, conforme mencionado anteriormente é interessante aprender mais sobre economia solidária para que a influência dessa inovação social aumente.

\section{CONSIDERAÇÕES FINAIS}

Analisar o impacto social do cooperativismo solidário em uma cooperativa de agricultura familiar envolve a compreensão de vários aspectos, que permeiam desde o que pode ser considerado empreendedorismo social, o que pode ser uma economia solidária e o que seria desenvolvimento sustentável. Após apropriação desses conceitos analisar as entrevistas e documentos em busca de se retratar o impacto social se tornou mais fácil.

Sobre o impacto social na COOPAFARO, cabe refletir sobre alguns pontos. No que diz respeito à inclusão social, nota-se que essa se interliga com inclusão produtiva e inclusão econômica. Basicamente, os cooperados se reunem em busca emancipação financeira. Porém não se tem trabalhado com a inclusão cultural internamente. Somente agentes externos como a EMATER e a UNICAFES estão trabalhando nesse tópico com alguns cooperados. Falta para esses agricultores adquirirem senso de união e colaboração para atingir seus objetivos, beneficiando todos os cooperados, seja por inovações sociais, sua missão, seu modelo de governança e sua sustentabilidade.

O esquecimento da participação na sociedade com base em inclusão social e inclusão cultural por parte dos cooperados é um problema. Cabe aos gestores fortalecer a sua relevância no desenvolvimento da gestão cooperativa, podendo, dessa forma alcançar os seus objetivos. É fundamental fortalecer as estratégias de educação e aprendizagem cooperativista, com programas de porte geral, executado com várias organizações em paralelo.

Há necessidade que surjam mais estudos que busquem descrever empiricamente esses impactos sociais para que a base de discussões sobre esses 3 temas aumente. Porém, a avaliação do desempenho social é um dos grandes desafios para os profissionais e pesquisadores na medida em que a verdadeira dificuldade pode não ser a medida em si, mas a forma como as medidas podem ser utilizadas para quantificar o desempenho do impacto do empreendedorismo social.

Sobre o cooperativismo solidário, vertente ainda pouco conhecida do cooperativismo, também deve-se desenvolver mais estudos. Acompanhar o Projeto de Lei 519/2015 e seus possíveis impactos. Durante a pesquisa notou-se a necessidade de se desenvolver mais estudos sobre políticas públicas que que incentivam a agricultura familiar, como o PNAE, PAA ou PRONAF. Acompanhar outras cooperativas filiadas à UNICAFES, também permitirá a 
comparação de diferentes realidades contribuindo para futuras aprendizagens sobre empreendedorismo social e economia solidária.

\section{AGRADECIMENTO}

Agradecemos ao Programa de Pós-Graduação em Administração da Universidade Federal de Rondônia (PPGA-UNIR); a Coordenação de Aperfeiçoamento de Pessoal de Nível Superior (CAPES); a Cooperativa de produtos e serviços agrícolas de agricultores familiares dos estados de Rondônia (COOPAFARO): a Empresa de Assistência Técnica e Extensão Rural do Estado de Rondônia (EMATER-RO); e a Secretaria Municipal de Agricultura e Abastecimento (SEMAGRIC).

Todos os autores declararam não haver qualquer potencial conflito de interesses referente a este artigo.

\section{REFERÊNCIAS}

ACI - International Co-operative Alliance. Disponível em: http://www.ica.coop. Acesso em: 08 jun. 2019.

ALEGRE, I., KISLENKO, S. Y BERBEGAL-M, J. Organized chaos: map-ping the definitions of social entrepreneurship, Journal of Social Entrepreneurship, v. 8, n. 2, p. 248-264, 2017. Disponível em:

https://www.tandfonline.com/doi/abs/10.1080/19420

676.2017.1371631. Acesso em: 14 mai. 2020.

AUSTIN, J.; WEI-SKILLERN, J. E.; STEVENSON, H. Social and Commercial Entrepreneurship: Same, Different, or Both?. Entrepreneurship Theory and Practice, v. 30, n. 1, p. 1-22, 2006. Disponível em: http://onlinelibrary.wiley.com/doi/10.1111/j.15406520.2006.00107.x/pdf. Acesso em: 08 jun. 2019.

BRASIL, Projeto de Lei 519 de 27 de fevereiro de 2015. Senado Federal, Brasília, DF, 27 de Fev. 2015. Disponível em: https://www.camara.leg.br/proposicoesWeb/fichadetr amitacao?idProposicao=953932. Acesso em: 08 jun. 2019.

CATTANI, A. D. (Org.) . A outra economia. Porto Alegre: Veraz, 2003.
CALGARO, R. Cooperativismo(s) brasileiro: hibridismo e contradições na caminhada das cooperativas. Gestão e Desenvolvimento em Revista, v. 2 , n. 2, p. 100-112, 2016. Disponível em: http://erevista.unioeste.br/index.php/gestaoedesenvolviment o/article/view/16170. Acesso em: 08 jun. 2019.

CERTO, S.; MILLER, T. Social entrepreneurship: Key issues and concepts. Business Horizons, v. 51, p. 267-271, 2008. Disponível em: https://econpapers.repec.org/article/eeebushor/v_3a51 _3ay_3a2008_3ai_3a4

_3ap_3a267-271.htm. Acesso em: 08 jun. 2019.

CONWAY, M. Y KALAKAY, J. The winding road of social entrepreneur-ship definitions: a systematic literature review. Social Enterprise Journal, v. 12, n. 2, p. 131-160, 2016. Disponível em: https://www.academia.edu/34949549/The_winding_r oad_of_social_entrepreneurship_definitions_a_syste matic_literature_review. Acesso em: 14 mai. 2020.

DAVIS, S. Social entrepreneurship: towards an entrepreneurial culture for social and economic development, 2002. Versão Eletrônica. Disponível em: $\quad$ https://www.ashoka.org/files/yespaper.pdf. Acesso em: 08 jun. 2019.

DEES, J. G. The meaning of social entrepreneurship, 2001. Versão Eletrônica. Disponível em: http://www.caseatduke.org/documents/dees_sedef.pdf . Acesso em: 08 jun. 2019.

DEFOURNY, J.; NYSSENS, M. El enfoque EMES de la empresa social desde una perspectiva comparada. CIRIEC-España. Revista de Economía Pública, Social y Cooperativa, v. 75, p. 7-34, 2012. Disponível em:

http://www.emes.net/uploads/media/EMES_WP_1301.pdf. Acesso em: 08 jun. 2019.

DEFOURNY, J.; NYSSENS, M. Fundamentals for an International Typology of Social Enterprise Models. Voluntas, 2017.

EMATER-RO. Empresa de Assistência Técnica e Extensão Rural do Estado de Rondônia. (2019). Desenvolvimento social. Disponível em: http://www.emater.ro.gov.br/ematerro/desenvolvimen to-social/. Acesso em: 08 jun. 2019.

GAIGER, L. I. G.; KUYVEN, P. S. Economia solidária e trajetórias de trabalho: uma visão retrospectiva a partir de dados nacionais. Revista Brasileira de Ciências Sociais, v. 35, n. 103, p. 1-17, $2020 . \quad$ Disponível em: 
https://www.scielo.br/pdf/rbcsoc/v35n103/01026909-rbcsoc-35-103-e3510304.pdf. Acesso em: 15 mai. 2020.

GODOY, A. S. O estudo de caso qualitativo. In: GODOI, C. K., BANDEIRA-DE-MELLO, R., SILVA, A. B. (Org.). Pesquisa qualitativa em estudos organizacionais: paradigmas, estratégias e métodos. 2. ed. São Paulo: Saraiva, 2010.

HARAYAMA, Y. E NITTA, Y. Transforming innovation to address social challenges. In OECD, fostering innovation to address social challenges: workshop proceedings (p. 11-17), 2011. Disponível em: http://www.oecd.org/science/inno/47861327.pdf. Acesso em: 08 jun. 2019.

LONG, N. Development sociology: actor perspectives. London and New York: Routlege, 2001.

MANCE, A. Redes de colaboração solidária: aspectos econômicos filosóficos: complexidade e libertação. São Paulo: Vozes, 2002.

MAIR, J.; MARTI, I. Social entrepreneurship research: a source of explanation, prediction and delight. Journal of World Business, v. 41, p. 36-44, $2006 . \quad$ Disponível em: http://citeseerx.ist.psu.edu/viewdoc/summary?doi=10 .1.1.210.199. Acesso em: 08 jun. 2019.

MAIR, J. Social entrepreneurship: taking stock and looking ahead. IESE Business School - University of Navarra Working Paper, 2010. Versão Eletrônica. Disponível em: http://www.iese.edu/research/pdfs/DI0888-E.pdf. Acesso em: 08 jun. 2019.

McCULLOCH, M.; RIDLEY-DUFF, R. To profit or not to profit? That is the wrong question. In: $7^{\text {th }}$ EMES International Research Conference on Social Enterprise. Conference paper $7^{\text {th }}$ EMES Sustainable development through social enterprise, cooperative and voluntary action Sheffield Hallam University. London, 2019, p.1-23. Disponível em: < https://emes.net/publications/conference-papers/7themes-conference-selected-papers/to-profit-or-not-toprofit-that-is-the-wrong-question/>. Acesso em 18 abr. 2020.

MERRIAM, S. B. Qualitative research: a guide to design and implementation. San Francisco: John Wiley and Sons, 2009.

MULGAN, G. Social innovation: what it is, why it matters and how it can be accelerated. Skoll Centre for Social Entrepreneurship Working Paper, 2007. Disponível http://www.sbs.ox.ac.uk/centres/skoll/research /Documents/Social\%20Innovation.pdf. Acesso em: 08 jun. 2019.

OECD. SMEs, entrepreneurship and innovation, 2010.Versão Eletrônica. Disponível em: http://www.keepeek.com/Digital-Asset-

Management/oecd/industry-and-services/smesentrepreneurship-and-innovation_9789264080355-en. Acesso em: 08 jun. 2019.

PARNELL, E. Cooperação: uma bela ideia. Lisboa: CASES, 2012.

PEREDO, A. M. E MCLEAN, M. Social entrepreneurship: A critical review of the concept. Journal of World Business, 2005. Disponível em: http://web.uvic.ca/ aperedo/page1/assets/Social\%20E nt\%20the \%20Concept.pdf. Acesso em: 08 jun. 2019.

QUIVY, R.; CAMPENHOUDT, L. V. Manual de investigação em ciências sociais (3a. Ed.). Lisboa: Gradiva, 2003.

STAKE, R. E. Case Studies. In: DENZIN, N. K. L., Y. S (Ed.). Handbook of Qualitative Research. 2 nd. Ed. London: Sage Publications, 2000.

SOUSA, M.; BAPTISTA, C. Como fazer investigação, dissertações, teses e relatórios: segundo Bolonha. Lisboa: Practor, 2011.

UNICAFES. União das Cooperativas da Agricultura Familiar e Economia Solidária. Documento Base V Congresso, Brasília, 2017a. Disponível em: <http://unicafes.org.br.>. Acesso em 10 jun. 2019.

UNICAFES. União das Cooperativas da Agricultura Familiar e Economia Solidária. Análise das ações desenvolvidas na fase piloto do PECSOL, Brasília, 2017b. Disponível em: <http://unicafes.org.br.>. Acesso em 10 jun. 2019.

UNICAFES Nacional. Programa de Educação do Cooperativismo Solidário (PECSOL). Módulo II modelo de gestão do cooperativismo solidário: participação e controle social. VITA CRED - VITA EDUC, Brasília, 2018.

WEERAWARDENA, J.; MORT, G. Investigating social entrepreneurship: a multidimensional model. Journal of World Business, v. 41, p. 21-35, 2006. Disponível em: http://www.topaz.org.il/_Uploads/ dbsAttachedFiles/social_entrepreneruship_multidime nsional_model_2006_JWB.pdf. Acesso em 10 jun. 2019. 
YIN, R. K. Case study research: design and methods (4a. ed.). SAGE Publication, 2009.

ZAHRA, S. A.; RAWHOUSER, H. N.; BHAWE, N.; NEUBAUM, D. O.; HAYTON, J. C. Globalization of social entrepreneurship opportunities. Strategic Entrepreneurship Journal, v. 2, n. 2, p. 117-131, $2008 . \quad$ Disponível em: http://www.irproje.com/userfiles/610033\%281\%29.p df. Acesso em 10 jun. 2019.

ZANCO, A, M. A contribuição do PECSOL para aprendizagem dos diretores como multiplicadores do conhecimento no cooperativismo. Francisco Beltrão, 2016. Disponível: tede.unioeste.br/bitstream/tede/3033/5/Alcidir\%20M. \%20Zanco2017.pdf. Acesso em 10 jun. 2019.
ZANCO, A. M.; CORBARI, F.; ALVES, A. F. Conexão entre as teorias de redes e as redes solidárias. Revista GeoPantanal, v. 24, p. 233-250, 2018. Disponível em:

http://desafioonline.ufms.br/index.php/revgeo/article/ view/6316/4965.>. Acesso em 10 jun. 2019.

ZANCO, A. M.; CORBARI, F.; ALVES, A. F. Conexão entre agricultura familiar e cooperativismo. Revista Orbis Latiana, v. 9, n. 1, p. 43-56, 2019. Disponível em:

https://revistas.unila.edu.br/orbis/article/view/1518/1 413.>. Acesso em 14 mai. 2020. 